\title{
Surgery versus Nerve Blocks for Lumbar Disc Herniation : Quantitative Analysis of Radiological Factors as a Predictor for Successful Outcomes
}

\author{
Joohyun Kim, M.D., Junseok W. Hur, M.D., Ph.D., Jang-Bo Lee, M.D., Ph.D., Jung Yul Park, M.D., Ph.D. \\ Department of Neurosurgery, College of Medicine, Korea University, Anam Hospital, Seoul, Korea
}

\begin{abstract}
Objective : To assess the clinical and radiological factors as predictors for successful outcomes in lumbar disc herniation (LDH) treatment. Methods : Two groups of patients with single level LDH (L4-5) requiring treatment were retrospectively studied. The surgery group (SG) included 34 patients, and 30 patients who initially refused the surgery were included in the nerve blocks group (NG). A visual analogue scale (VAS) for leg and back pain and motor deficit were initially evaluated before procedures, and repeated at 1, 6, and 12 months. Radiological factors including the disc herniation length, disc herniation area, canal length-occupying ratio, and canal area-occupying ratio were measured and compared. Predicting factors of successful outcomes were determined with multivariate logistic regression analysis after the optimal cut off values were established with a receiver operating characteristic curve.

Results : There was no significant demographic difference between two groups. A multivariate logistic regression analysis with radiological and clinical (12 months follow-up) data revealed that the high disc herniation length with cutoff value $6.31 \mathrm{~mm}$ [odds ratio (OR) 2.35; confidence interval (CI) 1.21-3.98] was a predictor of successful outcomes of leg pain relief in the SG. The low disc herniation length with cutoff value $6.23 \mathrm{~mm}$ (OR 0.05; Cl 0.003-0.89) and high baseline VAS leg (OR 12.63; Cl 1.64-97.45) were identified as predictors of successful outcomes of leg pain relief in the NG.

Conclusion : The patients with the disc herniation length larger than $6.31 \mathrm{~mm}$ showed successful outcomes with surgery whereas the patients with the disc herniation length less than $6.23 \mathrm{~mm}$ showed successful outcomes with nerve block. These results could be considered as a radiological criteria in choosing optimal treatment options for $\mathrm{LDH}$.
\end{abstract}

Key Words : Lumbar disc herniation · Surgery $\cdot$ Nerve block $\cdot$ Outcomes $\cdot$ Criteria.

\section{INTRODUCTION}

It is generally recommended to perform surgical treatment in lumbar disc herniation (LDH) for patients who suffer from cauda equina syndrome or intractable radicular pain, with or without neurological sensory/motor deficit ${ }^{21)}$. However, in numerous non-fatal cases, conservative treatment such as a nerve block could be effective ${ }^{9,20,24)}$. In patients with $\mathrm{LDH}$, a nerve block is generally performed before considering surgery for radicular pain as well ${ }^{3,10,13,20)}$. Recent randomized clinical trials show some evidence that the nerve block is cost-effective in the majority of cases compared to other operative interventions ${ }^{22,23)}$. Furthermore, potential complications associated with surgery such as revision, cerebrospinal fluid leakage, hematoma, and infection make spine physicians and patients prefer conservative treat- ments $^{1,7,14,17,25)}$.

In contrast, many spine surgeons claim that early surgery should be considered an appropriate approach for those patients who have lower thresholds for pain, those who demonstrate lower compliance with multiple nerve blocks for several months, and those who are more likely to fail with long-term pain control. They argue that early surgery in carefully selected patients with radicular pain can achieve more rapid pain relief than prolonged non-operative treatment ${ }^{14,17,20,28)}$. In addition, there is some evidence that time loss due to delayed surgery following the failure of conservative treatment can lead to unwanted results, such as development of the neuropathic pain, which can be refractory to usual or conventional treatments.

There are numerous studies comparing the clinical results between surgery and nerve blocks, but hardly any studies have

- Received : June 11, 2016 • Revised : July 29, 2016 • Accepted : August 16, 2016

- Address for reprints : Jung Yul Park, M.D., Ph.D.

Department of Neurosurgery, College of Medicine, Korea University, Anam Hospital, 73 Inchon-ro, Seongbuk-gu, Seoul 02841, Korea

Tel : +82-2-920-5729, Fax : +82-2-929-0629, E-mail : jypark98@korea.ac.kr

- This is an Open Access article distributed under the terms of the Creative Commons Attribution Non-Commercial License (http://creativecommons.org/licenses/by-nc/3.0) which permits unrestricted non-commercial use, distribution, and reproduction in any medium, provided the original work is properly cited. 
suggested decision algorithm and none of them analyzed radiographic data as predicting factors ${ }^{20,22,23,29)}$. Selecting appropriate treatment modalities for $\mathrm{LDH}$ requires thorough considerations of all aspects in order to make balanced decisions which are based on cost-effectiveness as well as possible side effects and complications. Thus, establishing radiological criteria as the prognostic factor for success of treatment between surgery and nerve blocks would be helpful in choosing an optimal treatment option. Authors in this paper have performed a quantitative analysis of radiological factors to determine the correlation of multiple factors with successful outcomes.

\section{MATERIALS AND METHODS}

\section{Patient population}

A retrospective review was performed to 64 adult patients who were treated with surgery or nerve blocks for single level LDH at our institution from January 2012 to December 2014, and they were followed up for at least a year. All of the patients were considered to be surgical candidates by two spine surgeons with more than 15 years of experience, and all of them had initially been recommended for surgery. The surgery group (SG) included 34 patients, and the nerve blocks group (NG) included 30 patients who initially refused the surgery.

The inclusion criteria of this study were as follows : Patients with 1) unilateral or bilateral intractable radicular leg pain and back pain with or without sensory/motor deficit after conservative treatment; 2) L4-5 level LDH confirmed by magnetic resonance imaging (MRI), and 3) organized medical records including both clinical and MRI data (pre- and post-treatment). A single level was selected to reduce the variables among multiple factors. In contrast, the following patients were excluded : 1) those with cauda equina syndrome; 2) those with progressive motor deficit; 3) those with previous histories of lumbar surgery; 4) those with histories of psychological disorder; and 5) those with radiological evidence of other pathologies correlated with symptoms such as spinal stenosis.

\section{Clinical analysis}

The clinical outcomes were investigated in the medical records of patients using a visual analogue scale (VAS) score for leg pain and back pain. Motor deficit was graded according to the Medical Research Council (MRC) scale ${ }^{8)}$. These clinical factors were evaluated pre-procedurally and were repeated at 1 month, 6 months, and 12 months in the outpatient clinic. A successful outcome was defined as excellent or good based on the MacNab classification $^{18)}$. The data of the patients' baseline demographic characteristics, comorbidities, and clinical factors are summarized in Table 1.

\section{Radiological analysis}

We analyzed pre-treatment and post-12 months MRI data. The disc herniation length, disc herniation area, canal cross-section length, canal cross-section area, canal length-occupying ratio, and canal area-occupying ratio were measured with ImageJ software, version 1.49 (NIH, Bethesda, MD, USA), obtained from an axial plane scan at the foraminal level pre-procedurally (Fig. 1). Post-procedure radiological factors were also measured after 12 months. Carlisle et al. ${ }^{4)}$ published predictive values of the need for surgical intervention by MRI analysis, and we used this model for radiological analysis. Canal area boundary trac-

Table 1. Patients' baseline demographics comparing the surgery and nerve blocks groups

\begin{tabular}{|c|c|c|c|}
\hline & $\begin{array}{l}\text { Surgery group } \\
\quad(\mathrm{n}=30)\end{array}$ & $\begin{array}{l}\text { Nerve blocks } \\
\text { group }(\mathrm{n}=34)\end{array}$ & $p$ \\
\hline Age, mean $\pm S D$, years & $44.9 \pm 14.4$ & $46.1 \pm 11.4$ & 0.62 \\
\hline Female sex, n (\%) & $13(43)$ & $14(41)$ & 0.86 \\
\hline $\mathrm{BMI},{ }^{\star}$ mean $\pm \mathrm{SD}$ & $23.9 \pm 3.2$ & $23.9 \pm 4.2$ & 0.65 \\
\hline Smoking, n (\%) & $8(26.7)$ & $10(29.4)$ & 0.81 \\
\hline Hypertension, n (\%) & $15(50)$ & $12(35.3)$ & 0.24 \\
\hline Diabetes, n (\%) & $3(10.0)$ & $3(8.8)$ & 0.87 \\
\hline $\begin{array}{l}\text { Duration, mean } \pm S D \text {, } \\
\text { months }\end{array}$ & $6.2 \pm 9.7$ & $3.8 \pm 4.7$ & 0.07 \\
\hline $\mathrm{SLR}$, mean $\pm \mathrm{SD},{ }^{\circ}$ & $55.3 \pm 24.2$ & $55.7 \pm 21.4$ & 0.90 \\
\hline VAS leg, ${ }^{\dagger}$ mean \pm SD & $4.5 \pm 1.0$ & $4.3 \pm 1.0$ & 0.61 \\
\hline VAS back, ${ }^{\dagger}$ mean \pm SD & $2.9 \pm 1.3$ & $2.6 \pm 1.4$ & 0.42 \\
\hline MRC grade, ${ }^{\ddagger}$ mean \pm SD & $4.4 \pm 1.4$ & $4.7 \pm 0.5$ & 0.76 \\
\hline
\end{tabular}

${ }^{*}$ The BMl is the weight in kilograms divided by the square of the height in meters, ${ }^{\dagger}$ The VAS ranges from 0 to 10 , with lower scores indicating less severe symptoms, ${ }^{\text {†TT }}$ The grade ranges from 0 to 5 , with a lower grade indicating severe motor deficit. BMI : body mass index, SLR : straight leg raising test, VAS : visual analogue scale, MRC : Medical Research Council

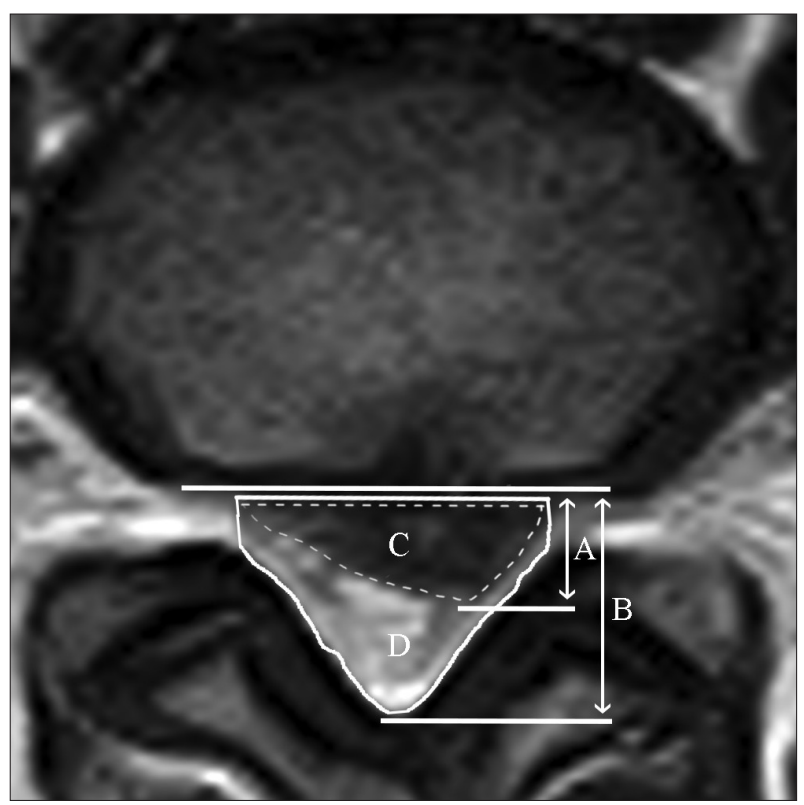

Fig. 1. The method of measurement of disc herniation and spinal canal length and area taken from an axial image at the $L 4-5$ foraminal level. $A$ : disc herniation length, $B$ : canal cross-section length, $C$ : disc herniation area, D : canal cross-section area. The canal length-occupying ratio of the herniated disc to the spinal canal, $A / B$, and the canal area-occupying ratio, $C / D$, were calculated. 
Table 2. Baseline radiological characteristics in both groups

\begin{tabular}{|c|c|c|c|}
\hline & Surgery group & Nerve blocks group & $p$ \\
\hline Disc herniation length, $\mathrm{mm}$ & $7.27 \pm 1.83$ & $6.72 \pm 2.45$ & 0.07 \\
\hline Canal cross-section length, mm & $20.03 \pm 1.66$ & $19.77 \pm 1.82$ & 0.48 \\
\hline Disc herniation area, $\mathrm{mm}^{2}$ & $120.02 \pm 33.92$ & $110.06 \pm 34.09$ & 0.10 \\
\hline Canal cross-section area, $\mathrm{mm}^{2}$ & $356.60 \pm 60.12$ & $366.81 \pm 73.71$ & 0.54 \\
\hline Canal length-occupying ratio, \% & $36.43 \pm 9.13$ & $34.20 \pm 12.29$ & 0.14 \\
\hline Canal area-occupying ratio, $\%$ & $33.66 \pm 7.74$ & $30.29 \pm 7.55$ & 0.11 \\
\hline
\end{tabular}

Values are presented as the mean \pm SD

ing was performed from neural arch posteriorly, $4 \mathrm{~mm}$ from the anterior surface of the superior facet on both sides anteriorly. The 4-mm antero-posterior (AP) distance in the foramen was estimated as sufficient to allow for normal nerve root function. The measured interpedicular distance was used as the canal width on the foraminal axial image of the same vertebra. Baseline radiological characteristics were summarized (Table 2).

\section{Nerve blocks technique}

We performed a transforaminal epidural steroid injection (TFESI) to relieve radicular pain with or without a nerve block of medial branch of posterior ramus (so called medial branch block : MBB) to relieve additional low back pain. In particular, the TFESI solution consisted of $1 \%$ lidocaine, dexamethasone (10 mg), and hyaluronidase (1500 IU) as an adjunct. Triamcinolone acetonide ( $40 \mathrm{mg}$ ) was used instead of dexamethasone for the MBB. Each patient received two nerve blocks at one week interval. A 23-gauge spinal needle was introduced to the target point, which was a so-called "safe triangle," i.e., above the nerve root and below the pedicle until bony contact was encountered. After verifying the correct needle positioning under AP fluoroscopic control, contrast solution was injected to confirm that the material was passing the selected nerve root and was not administered intravascularly. The finally image was verified and recorded. Then, $3 \mathrm{~mL}$ of mixed solution was injected into each targeted point. Following the procedure, the needle was withdrawn, the site was sealed with a sterile dressing, and the patients were monitored for 30 minutes for any untoward side effects. Each patient was evaluated 1, 6, and 12 months after the second nerve block. For patients with associated low back pain, additional MBBs were given above and below the involved level as described above. It was done in usual fashion with injection of additional $2 \mathrm{~mL}$ of mixed solution (without hyaluronidase) to each site.

\section{Surgical technique}

Under general anesthesia, the patient was placed prone on the operating table, and the thorax was supported on a Wilson frame (MDT Corp., Torrance, CA, USA). A 2-2.5 cm linear midline skin incision was performed at the targeted disc level. The unilateral fascia and paraspinal muscles were detached from the spinous process. A tubular retractor was inserted over the interlaminar area with the blade of the retractor medially. Following partial laminectomy under the microscope, the ligamentum flavum was detached from the lamina and removed. After identifying the disc material compressing the nerve root and dural $\mathrm{sac}$, the disc fragment was then removed. We removed disc material from the disc space when the disc was poorly hydrated. In well-hydrated discs, the non-herniated disc was preserved because it was beneficial for the preservation of the vitality of the motion segment in well-hydrated discs ${ }^{2}$. A nerve hook was used to explore the remnant disc material and to check for foraminal clearance. After meticulous hemostasis, saline irrigation was performed. Fascia and skin closure was obtained tightly with drains. Patients were discharged on the 1-week postoperative day, and the clinical outcome measurements were performed 1 month after surgery.

\section{Statistical analysis}

The Mann-Whitney U test was used for an analysis of the differences between the clinical and radiological factors of the SG and NG. Data are presented as mean \pm SD. A receiver operating characteristic (ROC) curve was obtained to determine the optimal cutoff values of radiological factors by plotting every possible cutoff value's sensitivity on the $y$ axis against 1-specificity on the $\mathrm{x}$ axis ${ }^{26)}$. Sensitivity was defined as the proportion of patients who were correctly classified in the successful outcome group, whereas specificity was defined as the proportion of patients who were correctly classified in the non-successful outcome group. The area under the ROC curve (AUC), which reflects the overall performance of diagnostic accuracy, was also analyzed with MedCalc software, version 16.4 (MedCalc Software, Mariakerke, Belgium). The values ranged from 0 to 1 . General guidelines have been suggested for interpreting the AUC : 0.5-0.7 represents no to low discriminatory power; $0.7-0.9$ represents moderate discriminatory power; and $>0.9$ represents high discriminatory power ${ }^{11,12,27)}$. With these cutoff values of radiological factors, multivariate logistic regression analysis was performed using the multiple clinical and radiological factors as independent variables and the successful outcome of the procedure as the dependent variable. $p<0.05$ was considered to be significant. Statistical calculations were performed using SPSS software, version 23.0 (IBM Corporation, Armonk, NY, USA). 


\section{RESULTS}

\section{Baseline characteristics}

There were no significant differences between the SG and NG in any of the clinical characteristics, including age, sex, comorbidities, duration and neurologic symptoms (Table 1). In addition, no significant differences in radiological characteristics were found. The baseline radiographic measurements for the SG and NG are provided in Table 2.

\section{Clinical outcomes after procedure}

There were no severe complications, including nerve root injuries, infections, or bleeding events, in both groups. VAS scores were decreased in both groups during the follow-up period. VAS leg at 1 month (SG : $1.50 \pm 0.68, \mathrm{NG}: 2.18 \pm 0.83, p<0.01$ ), 6 months (SG : $0.93 \pm 0.64, \mathrm{NG}: 1.71 \pm 1.00, p<0.01$ ) and 12 months (SG : $0.67 \pm 0.66$, NG : $1.24 \pm 0.74, p<0.01$ ) showed significant differences between two groups (Fig. 2A). VAS back at 1 month (SG : $0.67 \pm 0.71$, NG : $1.29 \pm 1.12, p=0.02$ ) also showed significant differences between two groups (Fig. 2B). However, VAS back at 6 months (SG : $0.53 \pm 0.63$, NG : $0.88 \pm 0.81, p=0.08$ ) and 12 months (SG : $0.37 \pm 0.49, \mathrm{NG}: 0.71 \pm 0.72, p=0.06$ ) showed no significant differences. MRC grade was also improved; however no significant differences were identified between the two groups at 1 month (SG : $4.57 \pm 0.97, \mathrm{NG}: 4.79 \pm 0.41, p=0.65)$ and 6 months (SG : $4.67 \pm 0.84, \mathrm{NG}: 4.85 \pm 0.36, p=0.51$ ) (Fig. $2 \mathrm{C}$ ). MRC grade at 12 months was significantly higher in the NG than in the SG (SG : $4.67 \pm 0.84, \mathrm{NG}: 4.97 \pm 0.17, p=0.03$ ).

\section{Changes in radiological factors after procedure}

Changes in radiological factors before and 12 months after the procedure were calculated (Table 3 ). The disc herniation length and canal length-occupying ratio were significantly decreased in the SG compare to the NG after 12 months from baseline ( $p=0.01$ ). Changes in the disc herniation area and in the canal area-occupying ratio were also larger in the SG than in the NG; however, the results were not statistically significant.

\section{Cutoff values for successful outcomes}

The ROC curve for successful leg pain relief at 12 months showed an AUC (95\% CI) for the disc herniation length of the SG of $0.66\left(0.46^{-0.82)}\right.$ and that of the NG of $0.64(0.46-0.80)$ (Fig. 3). The cutoff values (sensitivity, specificity) to distinguish between success and failure with the disc herniation length at 12 months were $6.31 \mathrm{~mm}(0.82,0.54)$ for the SG and $6.23 \mathrm{~mm}$ $(0.68,0.58)$ for the NG.

\section{Multivariate logistic regression analysis for successful outcomes}

Clinical outcomes was evaluated according to the MacNab classification. In the SG, the 22 patients (94\%) at 1 month, 29 patients (97\%) at 6 months and 29 patients (97\%) at 12 months experienced excellent or good leg pain relief (Fig. 4A). In the
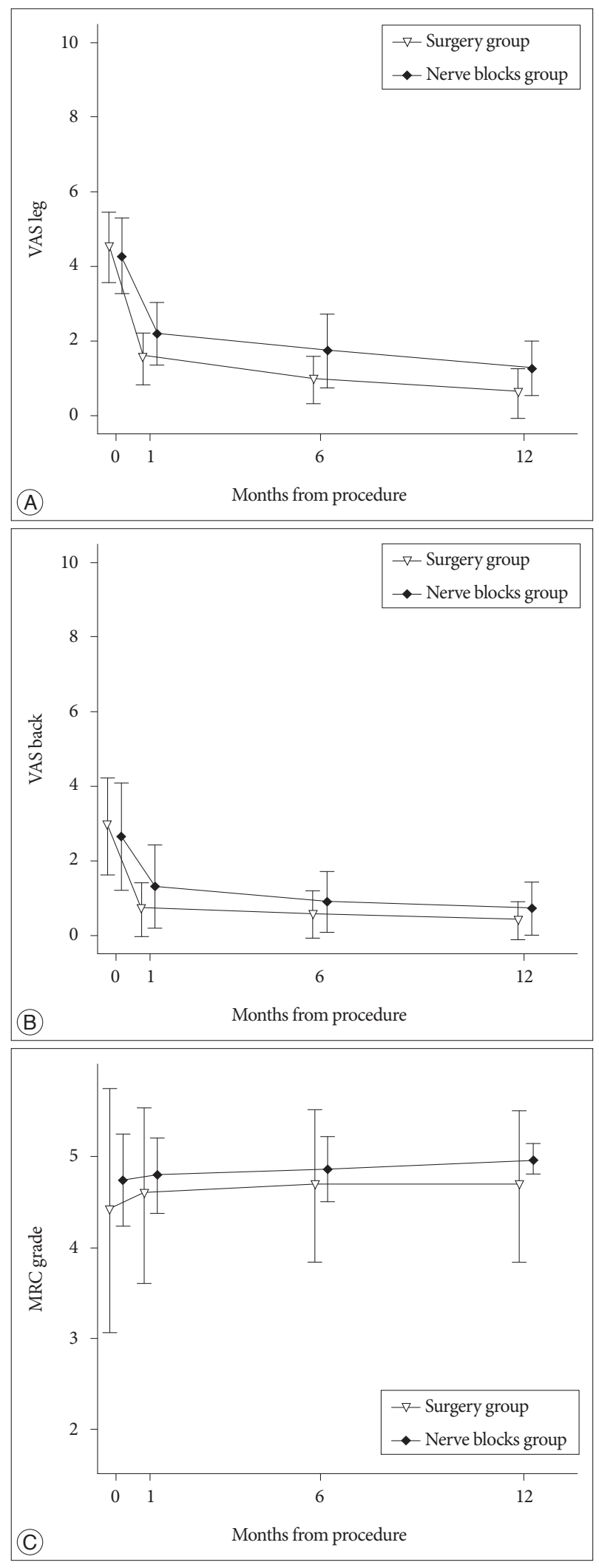

Fig. 2. Changes in the VAS scores and MRC grade before the procedure and repeated at 1 month, 6 months, and 12 months in both groups. A : Changes of VAS leg scores. $B$ : Changes of VAS back scores. $C$ : Changes of MRC grade. Values are presented as the mean \pm SD. VAS : visual analogue scale, MRC : Medical Research Council. 
NG, the 23 patients $(68 \%)$ at 1 month, 30 patients (88\%) at 6 months and 32 patients (94\%) at 12 months experienced excellent or good leg pain relief (Fig. 4B). Among the patients in SG, the 25 patients (83\%) at 1 month, 26 patients $(87 \%)$ at 6 months and 27 patients (90\%) at 12 months responded that they have experienced excellent or good back pain relief (Fig. 4C). Among the patients in NG, the 24 patients (70\%) at 1 month, 29 patients $(85 \%)$ at 6 months and 32 patients (94\%) at 12 months respond-

Table 3. Changes in radiological factors between pre-procedure and 12 months after the procedure

\begin{tabular}{lccc}
\hline & Surgery group & Nerve blocks group & $p$ \\
\hline$\Delta$ Disc herniation length, mm & $3.75 \pm 0.52$ & $0.19 \pm 0.58$ & $0.01^{\star}$ \\
$\Delta$ Canal cross-section length, mm & $-0.11 \pm 0.76$ & $0.31 \pm 0.67$ & 0.61 \\
$\Delta$ Disc herniation area, $\mathrm{mm}^{2}$ & $35.75 \pm 18.84$ & $11.90 \pm 18.78$ & 0.11 \\
$\Delta$ Canal cross-section area, $\mathrm{mm}^{2}$ & $0.30 \pm 2.43$ & $3.81 \pm 7.57$ & 0.26 \\
$\Delta$ Canal length-occupying ratio, $\%$ & $19.09 \pm 4.10$ & $0.53 \pm 2.37$ & $0.01^{\star}$ \\
$\Delta$ Canal area-occupying ratio, $\%$ & $9.86 \pm 5.92$ & $3.04 \pm 4.79$ & 0.26 \\
\hline
\end{tabular}

Values are presented as the mean \pm SD. $\triangle$ : Baseline values-Values at 12 months after the procedure. ${ }^{*} A$ statistical significant difference was observed between groups $(p<0.05)$
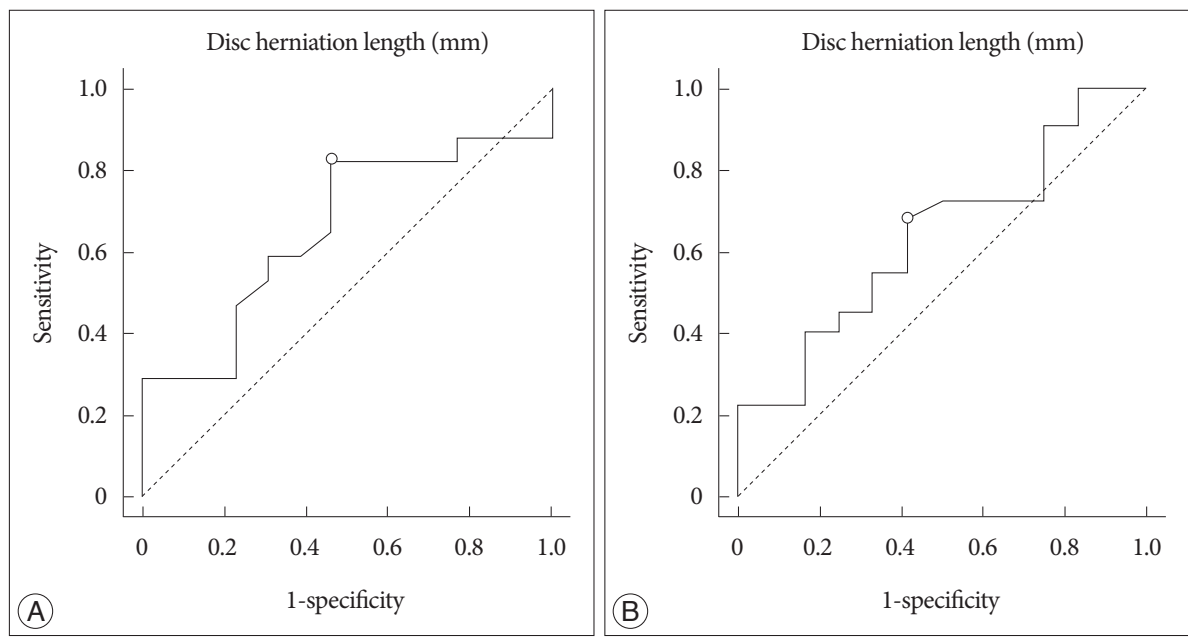

Fig. 3. A ROC curve was obtained to determine the optimal cutoff values (dot). The optimal cutoff values (sensitivity, specificity) were $6.31 \mathrm{~mm}(0.82$, $0.54)$ for the $S G(A)$ and $6.23 \mathrm{~mm}(0.68$, 0.58 ) for the NG (B). The AUC was 0.66 for the SG and 0.64 for the NG. SG : surgery group, $\mathrm{NG}$ : nerve blocks group.
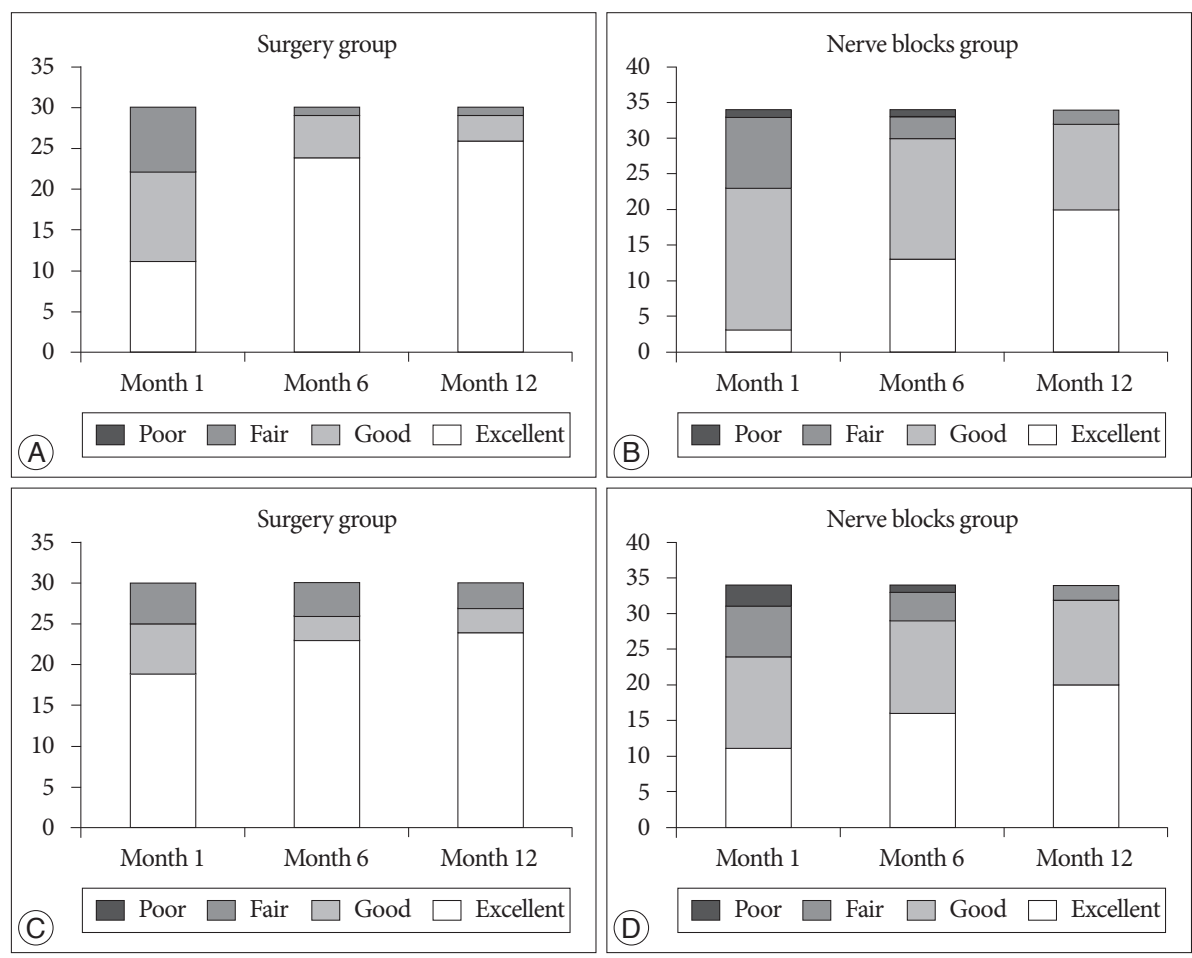

Fig. 4. Outcome evaluation according to MacNab classification. A : Leg pain relief for the SG. B : Leg pain relief for the NG. C : Back pain relief for the SG. $D$ : Back pain relief for the NG. SG : surgery group, NG : nerve blocks group. 
Table 4. Successful outcomes of leg and back pain relief at 12 months

\begin{tabular}{|c|c|c|c|c|}
\hline & \multicolumn{2}{|c|}{ Surgery group } & \multicolumn{2}{|c|}{ Nerve blocks group } \\
\hline & OR $(95 \% \mathrm{CI})$ & $p$ & OR $(95 \% \mathrm{CI})$ & $p$ \\
\hline \multicolumn{5}{|l|}{ Leg } \\
\hline Disc herniation length, $\mathrm{mm}$ & $2.35(1.21-3.98)$ & $<0.01^{\star}$ & $0.05(0.003-0.89)$ & $0.04^{*}$ \\
\hline Baseline VAS leg & - & - & $12.63(1.64-97.45)$ & $0.02^{*}$ \\
\hline \multicolumn{5}{|l|}{ Back } \\
\hline Baseline VAS back & - & - & $11.13(1.94-63.80)$ & $<0.01^{\star}$ \\
\hline
\end{tabular}

${ }^{\star}$ A statistical significant difference was observed between groups $(p<0.05)$. VAS : visual analogue scale

ed that they have experienced excellent or good back pain relief (Fig. 4D).

The odds ratio (OR) of the clinical and radiological factors for the successful outcomes of procedures were analyzed by multivariate logistic regression analysis. Multiple predictors of successful leg pain relief were identified (Table 4). The disc herniation length [OR 2.35; confidence interval (CI) 1.21-3.98] was a predictor for successful outcomes in the SG at 12 months, and the results in the NG revealed 2 independent predictors : disc herniation length (OR 0.05; CI 0.003-0.89) and baseline VAS leg (OR 12.63; CI 1.64-97.45). No significant radiological predictors were found of successful back pain relief in the two groups. However, high baseline VAS back predicted successful outcomes in the NG at 12 months (OR 11.13; CI 1.94-63.80).

\section{DISCUSSION}

We found that leg and back pain improvement was better in the SG during the follow-up period initially; however, the differences in the VAS leg between the two groups decreased from 6 months to 12 months, and VAS back at 12 months showed no significant difference. Based on these results, it is possible to assume that these differences could be further reduced over a longer-term follow-up period, although recurrence of disc herniation with the return of pain is also possible.

Surgery showed significant reductions in the disc herniation length and in the canal length-occupying ratio at 12 months after the procedure. However, nerve blocks also showed a decreasing tendency in radiological factors subsequent to the procedure. Matsubara et al. ${ }^{19)}$ reported that more degenerated discs and larger initial herniation had larger sizes of herniated fragments, which decreased in 32 patients treated conservatively with $\mathrm{LDH}$. In this study, there is no evidence of nerve block effect for natural regression of disc herniation neither in positive nor negative ways.

In studies evaluating the efficacy of surgery versus conservative treatment for $\mathrm{LDH}$, radiological predictors have been suggested $^{5,6,16,30)}$. Carlisle et al. ${ }^{4)}$ also showed a trend for patients treated with surgery toward having larger disc herniation area, corresponding to a larger percentage canal compromise than the conservatively treated group. However, the nerve block was not included in conservatively treated group on the above-mentioned studies. Therefore, authors have performed a compara- tive analysis between surgery and nerve blocks focusing on the radiological data which was not proposed elsewhere. From our study results, the patients with disc herniation length of L4-5 larger than $6.31 \mathrm{~mm}$ could be considered as candidates for surgical treatment, whereas those with disc herniation length less than $6.23 \mathrm{~mm}$ could be treated with nerve blocks. The radiological factors as cutoff values at 12 months had close to moderate discriminatory power.

While the study is still promising, it has limitations as well. It was performed retrospectively and the number of patients involved in this study was relatively small especially in the elderly population. Thus, further investigations with a greater number of patients will be needed for the general application of suggested cutoff values. A regression of the disc herniation could be important in correlation with improvement of symptoms and this could be also examined as a predictor. Single level $\mathrm{LDH}$, which does not represent the entire level of $\mathrm{LDH}$, was selected for the study, although L4-5 was the most common prolapsed level ${ }^{15)}$. In addition, the patients sample were not randomly selected and rather patients chose the preferred treatment modality.

Despite these limitations, to the best to our knowledge, this is the first report to demonstrate the radiological criteria for the LDH treatment options between surgery and nerve block. Large scale randomized control study should be performed in future.

\section{CONCLUSION}

Clinical and radiological factors of $\mathrm{LDH}$ patients were analyzed with quantitative methods. Disc herniation length was a good predictor for clinical outcome and could be considered as radiological criteria for choosing optimal treatment options for $\mathrm{LDH}$.

\section{References}

1. Asch HL, Lewis PJ, Moreland DB, Egnatchik JG, Yu YJ, Clabeaux DE, et al. : Prospective multiple outcomes study of outpatient lumbar microdiscectomy : should 75 to $80 \%$ success rates be the norm? J Neurosurg 96 (1 Suppl) : 34-44, 2002

2. Aydin Y, Ziyal IM, Duman H, Türkmen CS, Başak M, Sahin Y : Clinical and radiological results of lumbar microdiskectomy technique with preserving of ligamentum flavum comparing to the standard microdiskectomy technique. Surg Neurol 57 : 5-13; discussion 13-14, 2002

3. Beynon R, Hawkins J, Laing R, Higgins N, Whiting P, Jameson C, et al. : The diagnostic utility and cost-effectiveness of selective nerve root blocks 
in patients considered for lumbar decompression surgery : a systematic review and economic model. Health Technol Assess 17: 1-88, v-vi, 2013

4. Carlisle E, Luna M, Tsou PM, Wang JC : Percent spinal canal compromise on MRI utilized for predicting the need for surgical treatment in single-level lumbar intervertebral disc herniation. Spine J 5 : 608-614, 2005

5. Carragee EJ, Han MY, Suen PW, Kim D : Clinical outcomes after lumbar discectomy for sciatica : the effects of fragment type and anular competence. J Bone Joint Surg Am 85-A : 102-108, 2003

6. Carragee EJ, Kim DH : A prospective analysis of magnetic resonance imaging findings in patients with sciatica and lumbar disc herniation. Correlation of outcomes with disc fragment and canal morphology. Spine (Phila Pa 1976) $22: 1650-1660,1997$

7. Cheng J, Wang H, Zheng W, Li C, Wang J, Zhang Z, et al. : Reoperation after lumbar disc surgery in two hundred and seven patients. Int Orthop $37: 1511-1517,2013$

8. Compston A : Aids to the investigation of peripheral nerve injuries. Medical Research Council : Nerve Injuries Research Committee. His Majesty's Stationery Office : 1942; pp. 48 (iii) and 74 figures and 7 diagrams; with aids to the examination of the peripheral nervous system. By Michael O'brien for the Guarantors of Brain. Saunders Elsevier : 2010; pp. [8] 64 and 94 figures. Brain $133: 2838-2844,2010$

9. Cowan NC, Bush K, Katz DE, Gishen P : The natural history of sciatica : a prospective radiological study. Clin Radiol 46 : 7-12, 1992

10. Datta S, Manchikanti L, Falco FJ, Calodney AK, Atluri S, Benyamin RM, et al. : Diagnostic utility of selective nerve root blocks in the diagnosis of lumbosacral radicular pain : systematic review and update of current evidence. Pain Physician 16 (2 Suppl) : SE97-SE124, 2013

11. Greiner M, Pfeiffer D, Smith R : Principles and practical application of the receiver-operating characteristic analysis for diagnostic tests. Prev Vet Med $45: 23-41,2000$

12. Grzybowski M, Younger JG : Statistical methodology : III. Receiver operating characteristic (ROC) curves. Acad Emerg Med 4 : 818-826, 1997

13. Herron LD : Selective nerve root block in patient selection for lumbar surgery : surgical results. J Spinal Disord 2 : 75-79, 1989

14. Jacobs WC, van Tulder M, Arts M, Rubinstein SM, van Middelkoop M, Ostelo R, et al. : Surgery versus conservative management of sciatica due to a lumbar herniated disc : a systematic review. Eur Spine J 20 : 513-522, 2011

15. Kanna RM, Shetty AP, Rajasekaran S : Patterns of lumbar disc degeneration are different in degenerative disc disease and disc prolapse magnetic resonance imaging analysis of 224 patients. Spine J 14 : 300-307, 2014

16. Knop-Jergas BM, Zucherman JF, Hsu KY, DeLong B : Anatomic position of a herniated nucleus pulposus predicts the outcome of lumbar discectomy. J Spinal Disord 9:246-250, 1996
17. Lurie JD, Tosteson TD, Tosteson AN, Zhao W, Morgan TS, Abdu WA, et al. : Surgical versus nonoperative treatment for lumbar disc herniation : eight-year results for the spine patient outcomes research trial. Spine (Phila Pa 1976) 39:3-16, 2014

18. Macnab I : Negative disc exploration. An analysis of the causes of nerveroot involvement in sixty-eight patients. J Bone Joint Surg Am 53 : 891 903, 1971

19. Matsubara Y, Kato F, Mimatsu K, Kajino G, Nakamura S, Nitta H : Serial changes on MRI in lumbar disc herniations treated conservatively. Neuroradiology $37: 378-383,1995$

20. Narozny M, Zanetti M, Boos N : Therapeutic efficacy of selective nerve root blocks in the treatment of lumbar radicular leg pain. Swiss Med Wkly $131: 75-80,2001$

21. Overdevest GM, Vleggeert-Lankamp CL, Jacobs WC, Brand R, Koes BW, Peul WC, et al. : Recovery of motor deficit accompanying sciatica--subgroup analysis of a randomized controlled trial. Spine J 14 : 1817-1824, 2014

22. Riew KD, Park JB, Cho YS, Gilula L, Patel A, Lenke LG, et al. : Nerve root blocks in the treatment of lumbar radicular pain. A minimum fiveyear follow-up. J Bone Joint Surg Am 88 : 1722-1725, 2006

23. Riew KD, Yin Y, Gilula L, Bridwell KH, Lenke LG, Lauryssen C, et al. : The effect of nerve-root injections on the need for operative treatment of lumbar radicular pain. A prospective, randomized, controlled, doubleblind study. J Bone Joint Surg Am 82-A : 1589-1593, 2000

24. Saal JA, Saal JS : Nonoperative treatment of herniated lumbar intervertebral disc with radiculopathy. An outcome study. Spine (Phila Pa 1976) $14:$ : 431-437, 1989

25. Sin AH, Caldito G, Smith D, Rashidi M, Willis B, Nanda A : Predictive factors for dural tear and cerebrospinal fluid leakage in patients undergoing lumbar surgery. J Neurosurg Spine 5 : 224-227, 2006

26. Solberg T, Johnsen LG, Nygaard ØP, Grotle M : Can we define success criteria for lumbar disc surgery? : estimates for a substantial amount of improvement in core outcome measures. Acta Orthop 84 : 196-201, 2013

27. Swets JA : Measuring the accuracy of diagnostic systems. Science 240 : 1285-1293, 1988

28. Weber $\mathrm{H}$ : Lumbar disc herniation. A controlled, prospective study with ten years of observation. Spine (Phila Pa 1976) $8: 131-140,1983$

29. Weiner BK, Fraser RD : Foraminal injection for lateral lumbar disc herniation. J Bone Joint Surg Br 79: 804-807, 1997

30. Wittenberg RH, Lütke A, Longwitz D, Greskötter KH, Willburger RE, Schmidt K, et al. : The correlation between magnetic resonance imaging and the operative and clinical findings after lumbar microdiscectomy. Int Orthop 22 : 241-244, 1998 